\title{
Avaliação da degradação ambiental de parte do Seridó Paraibano ${ }^{1}$
}

\author{
Humberto G. Candido², Marx P. Barbosa ${ }^{3} \&$ Miguel J. da Silva ${ }^{4}$
}

\begin{abstract}
${ }^{1}$ Parte da dissertação de mestrado do primeiro autor, apresentada ao Curso de Pós-Graduação em Engenharia Agrícola da Universidade Federal da Paraíba, Campina Grande, PB, Campus II

2 Escola Agrotécnica Federal de Uberaba, MG. Fone: (34) 336-4844. E-mail gois@mednet.com.br (Foto)

3 DEAg/CCT/UFCG. Fone: (83) 333-2355. E-mail marx@Imrs-semarh.ufpb.br

${ }^{4}$ DEAg/CCT/UFCG. Fone: (83) 333-2355. E-mail miguel@Imrs-semarh.ufpb.br
\end{abstract}

Protocolo $120-6 / 8 / 2001$

\begin{abstract}
Resumo: O Seridó Oriental Paraibano tem se caracterizado, nos últimos anos, por uma intensa degradação de suas terras agrícolas como resultado dos efeitos do evento ENOS, refletidos em prolongados períodos de seca. A pesquisa em questão tratou da avaliação da degradação ambiental da região, estudando-se $947,81 \mathrm{~km}^{2}$ de seu território. Os parâmetros utilizados foram: vegetação, topografia, solo/geologia, ecologia, mecanização, área agrícola, densidade populacional (inclusive a migração) e pecuarização, que definiram quatro níveis de degradação ambiental: baixo, moderado, grave e muito grave, confirmando a gravidade da ocorrência dos processos de degradação/ desertificação das terras, uma vez que $44,86 \%$ da área estudada foram classificados com o índice grave de degradação e 2,24\% em muito grave. Com as áreas classificadas como muito grave, está relacionada à formação dos chamados "núcleos de desertificação".
\end{abstract}

Palavras-chave: degradação ambiental, desertificação

\section{Evaluation of the environmental degradation in the region of Seridó of Paraíba - Brazil}

\begin{abstract}
The eastern region of Seridó, Paraíba, has been characterized in the last years by an intense degradation of the agricultural lands due to the extensive drought periods, caused by ENSO. This paper deals with the evaluation of the environmental degradation of the area, a territory of about $947.81 \mathrm{~km}^{2}$. The parameters used to classify the degradation levels were vegetation, topography, soil/geology, ecology, mechanization, agricultural area, population density (including the migration) and cattle raising, that defined four levels of environmental degradation: lower, moderate, serious and very serious. The analysis of these parameters confirmed the gravity of the occurrence of the degradation/desertification processes of the lands. For $44.86 \%$ of the studied area the degradation index was classified as serious and for $2.24 \%$ very serious. In the areas classified as very serious, the formation of the so called "desertification nucleus", was observed.
\end{abstract}

Key words: environmental degradation, desertification

\section{INTRODUÇÃO}

A Paraíba é o Estado brasileiro que possui o maior percentual de áreas com nível de desertificação muito grave (29\%), afetando o dia-a-dia de uma população de mais de 653 mil pessoas. Pouco mais de $70 \%$ do território paraibano, onde residem 1,66 milhão de pessoas ( $52 \%$ do total da população) são afetados pelo problema. O sobrepastoreio, a alta densidade populacional registrada em várias localidades, os constantes desmatamentos e o manejo ambiental sem planejamento fazem com que grande parte das terras do Estado enfrente sérios problemas de erosão e redução da fertilidade potencial dos solos (Monteiro, 1995).

Apesar da importância dos temas relacionados a desertificação, as pesquisas ainda são muito limitadas, especialmente na Paraíba. Os trabalhos desenvolvidos a nível local são poucos, predominando aqueles de caráter geral, para toda a região Nordeste, sem se contar que apenas uma pequena quantidade desse material está disponível, mesmo em bibliotecas públicas (Rodrigues, 1997).

Objetivou-se, através desta pesquisa, avaliar os atuais níveis da degradação ambiental no Seridó Oriental Paraibano, tendo como ferramentas básicas o sensoriamento remoto e o SIG. 


\section{MATERIAL E MÉTODOS}

Imagens de satélite do TM/Landsat-5 (bandas 3 e 4); mapas temáticos de Fernandes (1997) - solos, declividade, susceptibilidade à erosão, drenagem, uso da terra e aptidão agrícola; cartas topográficas da SUDENE na escala de 1:100.000; GPS e os softwares SGI-340 (versão 2.5E), SPRING 3.3 e CorelDRAW.8, foram os materiais utilizados nesta pesquisa.

A metodologia baseou-se nos trabalhos de Baumgratz et al. (1986); ITDG (1994) e Ferreira et al. (1997). Na avaliação da degradação ambiental foram utilizados os parâmetros vegetação, topografia, solo/geologia, ecologia, mecanização, área agrícola, densidade populacional e pecuarização e os dados extraídos das imagens TM, com apoio das cartas topográficas, dos mapas temáticos e dados de campo georreferenciados, resultando em 130 zonas homólogas de tonalidades de cinza, numeradas seqüencialmente (Figura 1). Na avaliação dos níveis de degradação ambiental para a sua classificação em baixo, moderado, grave e muito grave foram definidos pesos (Tabela 1) de acordo com a vulnerabilidade do terreno. Por exemplo, uma determinada área com uma vegetação fechada e uma declividade baixa $(<15 \%)$ é muito menos vulnerável a

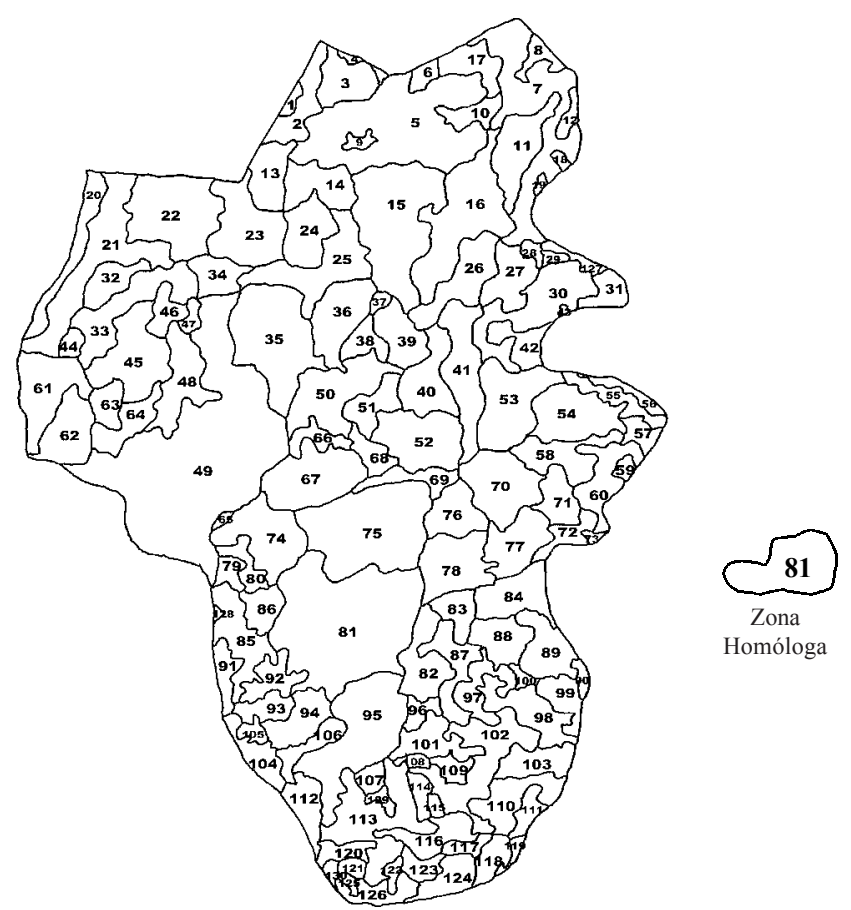

Figura 1. Mapa das zonas homólogas

Tabela 1. Avaliação da vulnerabilidade ambiental das zonas homólogas fotointerpretadas

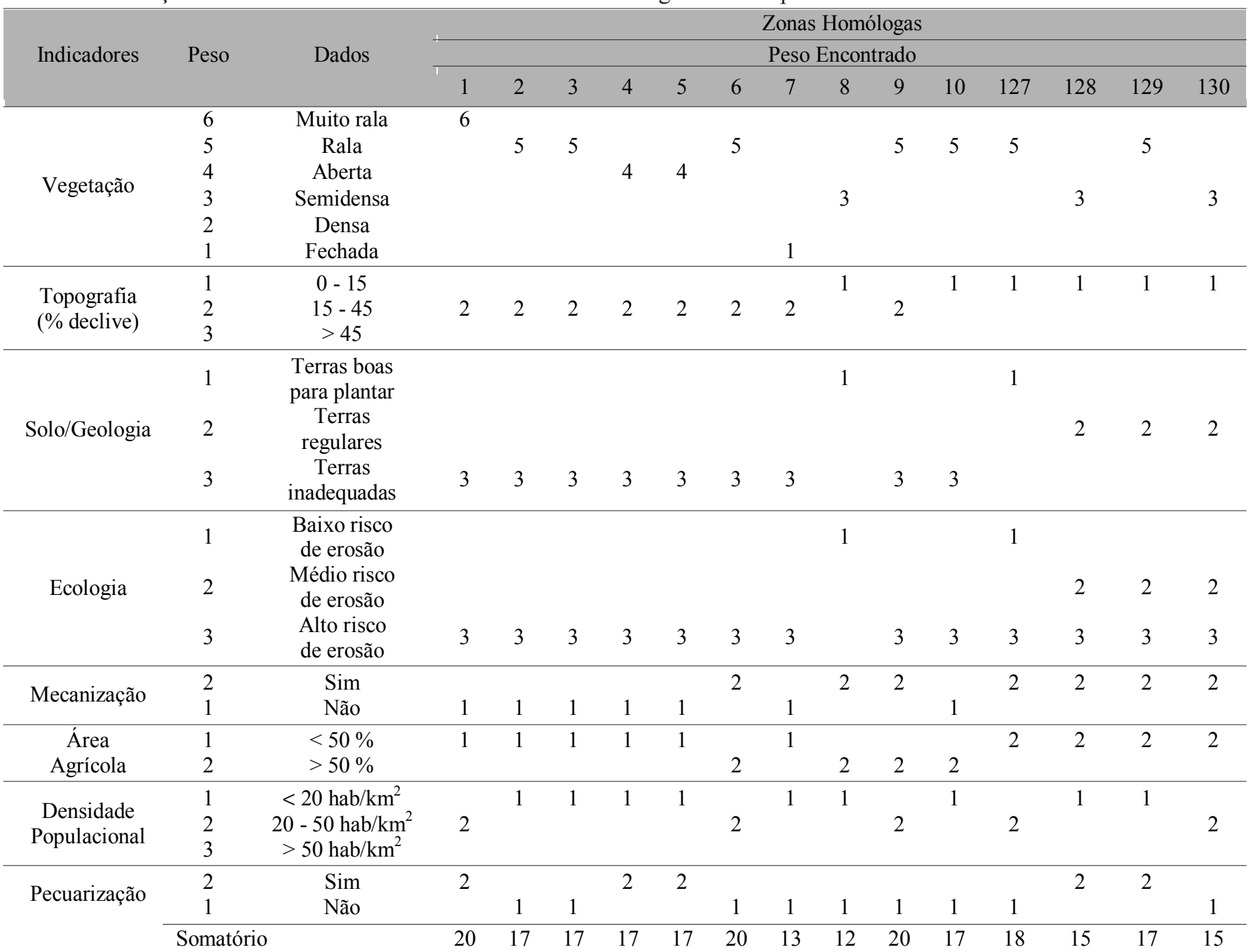

Os resultados das zonas homólogas de 11 a 126 não foram apresentados para evitar que o documento se torne muito extenso; porém os procedimentos adotados para estas zonas são idênticos aos demonstrados neste trabalho 
degradação dos solos, do que uma área com vegetação muito rala e uma declividade muito alta $(>45 \%)$.

A soma total dos pesos de cada indicador ou parâmetro, para cada uma das 130 zonas homólogas analisadas, foi de 24 pontos, sendo o máximo que se pode atingir por zona. Para o nível de degradação baixo adotaram-se os valores $\leq 12$. Para o nível moderado, consideraram-se os valores situados no intervalo de 13 a 16 . As zonas com peso de 17 a 19 pontos foram classificadas como grave e as com peso $\geq 20$, como muito grave (Tabela 2).

\section{RESULTADOS E DISCUSSÃO}

No mapa de degradação ambiental (Figura 2) está representada a distribuição espacial dos quatro níveis de degradação definidos para a área de estudo.

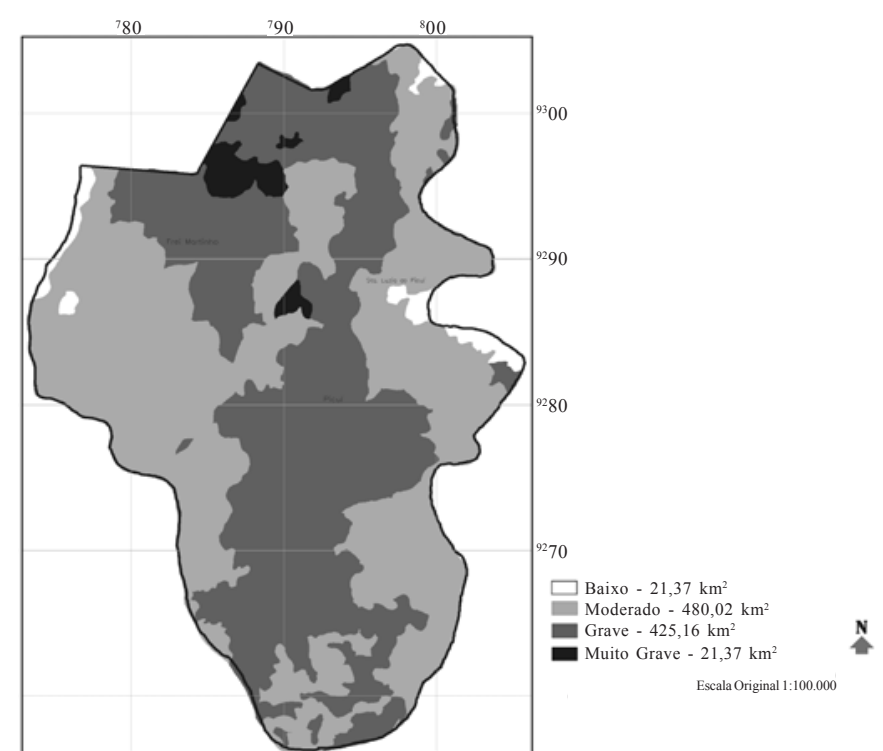

Figura 2. Níveis de degradação ambiental

Os níveis de degradação ambiental baixo e muito grave ocupam as menores áreas. $\mathrm{O}$ fato da classe de degradação muito grave possuir a menor percentagem de espaço ocupado $(2,24 \%)$ não deve ser desprezada, pois é nesta classe que estão surgindo os chamados "núcleos de desertificação". Por outro lado foi encontrada uma pequena parcela com índice baixo de degradação $(2,25 \%)$, o que é muito pouco para as necessidades de sustentabilidade da área. Cerca de $50,65 \%$ da área possuem o índice de degradação moderado, e 44,86\% apresentam índice de degradação grave.
Pelo percentual de degradação da classe grave (praticamente ocupando a metade da área de estudo) observa-se grande desgaste e um sério comprometimento das condições de sustentabilidade das terras.

\section{Características principais das classes de degradação am- biental}

Nível de degradação baixo:

- Geralmente apresenta relevo plano, suave ondulado a ondulado

- Solos dominantes: latossolos

- Uso da terra: agricultura

- Vegetação: vegetação natural (em número não muito significativo devido ao uso intenso do solo na agricultura, apresentando-se na imagem de satélite e no campo em concentrações variando de fechada a muito rala).

Nível de degradação moderado:

- Geralmente apresenta relevo suave ondulado, ondulado a fortemente ondulado;

- Solos dominantes: regossolos e litólicos;

- Uso da terra: agricultura, pastoreio e extração de lenha;

- Vegetação: pastagem nativa, palma forrageira, vegetação natural (caatinga semidensa a aberta).

Nível de degradação grave:

- Geralmente, apresenta relevo ondulado, fortemente ondulado e montanhoso

- Solos dominantes: litólicos

- Uso da terra: pastoreio, mineração

- Vegetação: vegetação natural (caatinga aberta à rala), pastagem natural, palma forrageira.

Nível de degradação muito grave:

- Geralmente apresenta relevo fortemente ondulado a montanhoso

- Solos dominantes: litólicos

- Uso da terra: pastoreio, mineração

- Vegetação: vegetação natural (caatinga muito rala).

As análises dos dados coletados em campo permitiram uma avaliação do quadro socioeconômico e ambiental, que indica alta deterioração das condições de vida, e denuncia as dificuldades severas das famílias em se manter, mostrando o

Tabela 2. Classificação das zonas homólogas por níveis de degradação ambiental, conforme a amplitude dos pontos ou pesos encontrados

\begin{tabular}{|c|c|c|c|c|}
\hline & $\begin{array}{c}\text { Baixo } \\
\leq 12 \text { pontos }\end{array}$ & $\begin{array}{c}\text { Moderado } \\
13-16 \text { pontos }\end{array}$ & $\begin{array}{c}\text { Grave } \\
17-19 \text { pontos }\end{array}$ & $\begin{array}{l}\text { Muito Grave } \\
\geq 20 \text { pontos }\end{array}$ \\
\hline 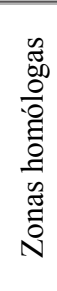 & $\begin{array}{l}8,20,42,44 \\
55,56\end{array}$ & $\begin{array}{l}7,11,15,21,27,28,29,30,31,32, \\
33,36,41,43,45,46,47,48,49,50, \\
53,54,58,59,60,61,62,63,64, \\
66,71,72,73,74,79,80,83,84,85, \\
86,87,88,89,90,91,92,97,98,99, \\
100,103,104,108109,110,111, \\
113,114,115,117,119,121,123, \\
126,127,130\end{array}$ & $\begin{array}{l}2,3,4,5,10,12,16,17,18,19,22, \\
23,24,25,26,34,35,37,39,40,51, \\
52,57,65,67,68,69,70,75,76,77, \\
78,81,82,93,94,95,96,101,102, \\
105,106,107,112,116,118,120, \\
122,124,125\end{array}$ & $1,6,9,13,14,38$ \\
\hline
\end{tabular}


completo abandono do homem do campo. Verificou-se que a mulher rural, embora ainda considerada socialmente inferior ao homem, vem assumindo funções que eram consideradas específicas ao homem. Neste contexto, o papel da mulher tem que ser valorizado e reavaliado. Assim, é de suma importância envolver a mulher rural nos programas ambientais conservacionistas, inclusive em atividades remunerativas, valorizando o seu trabalho e capacitá-la em atividades de criação e plantio, organizando-a em grupos de mulheres fortalecendo, assim, a solidariedade, a sua capacidade, o seu valor e o seu potencial.

\section{CONCLUSÕES}

1. A metodologia mostrou-se eficiente na realização dos estudos da degradação ambiental/desertificação, preenchendo uma lacuna deixada por boa parte dos trabalhos de aplicação das técnicas de sensoriamento remoto e SIG na análise da degradação ambiental, quando ela contempla os aspectos sociais, e as questões de gênero, enfocando o seu aspecto intermultidisciplinar.

2. O alto índice de degradação grave e muito grave chegando a quase $50 \%$ da área estudada, deve ser tomado como um alerta pelos tomadores de decisão, tanto na esfera estadual e federal, como na municipal, para que medidas mitigadoras urgentes sejam tomadas, prevenindo desta forma um desastre eminente para toda a região, que é a desertificação generalizada, pois os resultados da pesquisa mostram que 2,28\% $\left(21,68 \mathrm{~km}^{2}\right)$ já são caracterizados pelo desenvolvimento dos núcleos de desertificação.
3. O poder público precisa definir urgentemente políticas públicas, visando ao desenvolvimento sustentável com a diminuição dos riscos, e que venham consolidar a participação da mulher rural nas atividades socioeconômicas e familiar.

\section{LITERATURA CITADA}

Baumgratz, S.S.; Boaventura, R.S. Erosão acelerada e desertificação em Minas Gerais. In: Seminário sobre Desertificação no Nordeste. 1986, Recife. Documento final. Brasília: SEMA, 1986. p. 84-110.

Fernandes, M. de F. Avaliação da aptidão agrícola das terras de parte do setor leste da bacia do Rio Seridó usando sensoriamento remoto e geoprocessamento. Campina Grande: 1997. 185p. Dissertação Mestrado

Ferreira, D.G, Rodrigues, V., Melo, H. P. Avaliação do quadro da desertificação no Nordeste do Brasil: diagnósticos e perspectivas. Teresina: UFPI/Núcleo DESERT, 1997. 22p.

ITDG - Intermediate Technology Development Group. Propuesta metodológica para el analisis de vulnerabilidad en la region San Martín, Peru. Lima, 1994. np.

Monteiro, M. Desertificação ameaça o nordeste brasileiro. Revista Ecologia e Desenvolvimento, Rio de Janeiro, $\mathrm{n}^{\circ}$ 51, p.15-19, mai. 1995.

Rodrigues, V. Pesquisa dos estudos e dados existentes sobre desertificação no Brasil. Brasília: Projeto BRA 93/036, 1997. 65p.

Vasconcelos Sobrinho, J. de. Metodologia para identificação de processos de desertificação: manual de indicadores. Recife: SUDENE-DDL, 1978.22p. 